CLINICAL STUDY

\title{
Malignant and benign thyroid nodules after total body irradiation preceding hematopoietic cell transplantation during childhood
}

\author{
Maritza Vivanco $^{1}$, Jean-Hugues Dalle ${ }^{2,6}$, Corinne Alberti ${ }^{3,4,6}$, Brigitte Lescoeur ${ }^{2}$, Karima Yakouben ${ }^{2}$, \\ Jean-Claude Carel ${ }^{1,4,6}$, André Baruchel ${ }^{2,6}$ and Juliane Léger ${ }^{1,5,6}$ \\ ${ }^{1}$ Assistance Publique-Hôpitaux de Paris, Service d'Endocrinologie Pédiatrique, Centre de Référence des Maladies Endocriniennes Rares de la Croissance, \\ Hôpital Robert Debré, 48 Boulevard Sérurier, 75019 Paris, France, ${ }^{2}$ Assistance Publique-Hôpitaux de Paris, Service d'Hématologie, Hôpital Robert Debré, \\ 75019 Paris, France, ${ }^{3}$ Assistance Publique-Hôpitaux de Paris, Unité d'Epidémiologie Clinique, Hôpital Robert Debré, 75019 Paris, France, ${ }^{4}$ Inserm, \\ CIE 5, 75019 Paris, France, ${ }^{5}$ Inserm, UMR 676, 75019 Paris, France and ${ }^{6}$ Univ Paris Diderot, Sorbonne Paris Cité, 75019 Paris, France
}

(Correspondence should be addressed to J Léger at Assistance Publique-Hôpitaux de Paris, Service d'Endocrinologie Pédiatrique, Centre de Référence des Maladies Endocriniennes Rares de la Croissance, Hôpital Robert Debré; Email: juliane.leger@rdb.aphp.fr)

\begin{abstract}
Background: The risk of radiation-induced benign and malignant thyroid nodules is well known. Objective: The aim of this study was to determine the occurrence of thyroid nodules and carcinomas after fractionated total body irradiation (TBI) preceding hematopoietic stem cell transplantation (HSCT) for malignant hematological disease during childhood.

Methods: We conducted a retrospective university hospital-based observational study. The participants were 76 patients receiving fractionated TBI between 1989 and 2009 as part of the conditioning regimen for HSCT to treat malignant hematological disease, with a median age of 8.2 (5.7-11.4) years, for whom the last ultrasound examination was performed at a median age of $14.2(11.2-17)$ years. The main outcome measure was cumulative incidence of thyroid nodules detected by ultrasound scans followed by biopsy if necessary.

Results: Thyroid nodules were examined in 21 (28\%) patients, six (29\%) of whom were diagnosed with thyroid carcinoma at the age of 2.2-18.6 years after TBI. The cumulative incidence of nodule occurrence increased with increasing time from diagnosis. The 10-year cumulative incidence of benign and malignant thyroid nodules was 16\% (95\% confidence interval (CI) 4-27\%) and $8 \%$ $(95 \%$ CI $0-16 \%)$ respectively. Seventeen (22\%) patients had hypothyroidism (compensated $n=12$, in five patients it was transient). No significant independent risk factors were identified in the multivariable competing risk model as a function of nodule occurrence.

Conclusion: Short-term and life-long monitoring, with screening for nodules of the thyroid gland using ultrasound scans, is recommended for survivors subjected to TBI for HSCT during childhood.
\end{abstract}

European Journal of Endocrinology 167 225-233

\section{Introduction}

The thyroid gland is susceptible to irradiation, and exposure to radiation in childhood increases the risk of both benign and malignant thyroid nodules $(1,2,3,4$, 5). Studies on patients receiving irradiation treatment for various cancers have reported a high frequency of benign and malignant thyroid nodules. The reported relative risks for thyroid nodules among the survivors of pediatric cancers who have undergone radiation therapy vary greatly, with an incidence of malignancy of $10-40 \%(6,7,8,9,10,11,12,13)$. Analysis of studies evaluating thyroid carcinoma after exposure to external radiation during childhood showed that the dose-response relationship was linear, although the risk appeared to plateau at the highest dose, with risk appearing to slightly decrease at doses of even more than $2000 \mathrm{cGy}(9,11,13,14,15,16)$. Age at irradiation, sex, and duration of follow-up have also been identified as determinants influencing the risk of thyroid tumors. Most of these studies included patients with Hodgkin disease and non-Hodgkin lymphoma or patients treated by cranial and craniospinal radiotherapy for acute lymphoblastic leukemia $(17,18,19$, 20). However, the risk of malignancy following radiation exposure seems to depend not only on the dose of radiation administered but also on the type of the first cancer, the type of chemotherapy used, and the resulting immunodeficiency and/or associated autoimmune disorders $(16,21)$. Only a few studies have investigated survivors who received total body irradiation (TBI) for hematopoietic stem cell transplantation (HSCT). These studies included patients receiving various type of TBI according to various schedules, 
as a single dose or fractionated, with a total dose of 990-1200 cGy; some of these patients also received cranial radiation as a first-line treatment for various hematological and oncological diseases (22, 23, 24, 25, 26, 27). Moreover, the method of screening differed between studies, with some studies using more sensitive methods than others. Physical examination is not a reliable method for detecting thyroid nodules, and ultrasound scans are generally required for thyroid nodule screening (28) followed by fine-needle aspiration biopsy (FNAB) for the management of suspected lesions (29).

In this study, we aimed to retrospectively determine the occurrence of thyroid nodules and thyroid carcinoma after fractionated TBI preceding HSCT for childhood malignant hematological disease (CMHD).

\section{Patients and methods}

All patients who had undergone TBI as part of a conditioning regimen before HSCT for a CMHD in our department, before the age of 18 years between 1989 and 2009, were studied. These patients $(n=103)$ included 95 survivors, 19 of whom were lost to follow-up $(n=9)$ or not screened by thyroid ultrasound scan $(n=10)$. The clinical characteristics of the participants $(n=76,80 \%$ of the initial cohort) and nonparticipants $(n=19)$ are presented in Table 1 . The study population was representative of the entire population treated by TBI for CMHD during childhood, as shown by the distributions of sex and type of cancer, median age at TBI and HSCT, age at hematological disease diagnosis, number of remissions before HSCT, presence of graft vs host disease (GVHD), and/or additional cranial irradiation performed at any time before TBI.

Participants were followed for a median interval of 5.1 (2.5-9.5) years after TBI and HSCT. Pediatricians did not follow a study protocol for thyroid ultrasound assessment. Thyroid ultrasound scans and thyroid function assessments were, therefore, performed at various times during follow-up and/or at the time of the study.

Subclinical peripheral compensated hypothyroidism was defined as serum TSH concentrations $>5 \mathrm{mIU} / \mathrm{l}$ (the upper limit of our reference range), up to a conventional limit of $10 \mathrm{mIU} / \mathrm{l}$, with serum-free thyroxine $\left(\mathrm{FT}_{4}\right)$ concentrations within our reference range (11-21 pmol/l). Overt peripheral hypothyroidism was defined as a serum TSH concentration $>10 \mathrm{mIU} / \mathrm{l}$ and central hypothyroidism was defined as a serum $\mathrm{FT}_{4}$ concentration $\leq 10 \mathrm{pmol} / \mathrm{l}$, with normal TSH levels.

The study was approved by the Institutional Review Board of our faculty. Informed consent for the evaluations and treatments was obtained from the subjects or their parents.
Table 1 Characteristics of participants and nonparticipants. Results are expressed as medians (25th-75th percentile).

\begin{tabular}{|c|c|c|c|}
\hline & $\begin{array}{c}\text { Nonparticipants } \\
(n=19)\end{array}$ & $\begin{array}{l}\text { Participants } \\
\quad(n=76)\end{array}$ & $P$ value \\
\hline \multicolumn{4}{|l|}{ Sex } \\
\hline Male & $13(68 \%)$ & $43(57 \%)$ & 0.35 \\
\hline Female & $6(32 \%)$ & $33(43 \%)$ & \\
\hline $\begin{array}{l}\text { Age at diagnosis } \\
\text { of hematological } \\
\text { disease (years) }\end{array}$ & $6.5(3.4-10.2)$ & $5.4(3.0-9.3)$ & 0.47 \\
\hline Age at TBI (years) & $8.1(6.2-11.2)$ & $8.2(5.7-11.4)$ & 0.84 \\
\hline \multicolumn{4}{|l|}{ Type of cancer } \\
\hline $\mathrm{L}$ & 0 & $2(3 \%)$ & 0.66 \\
\hline BAL & 0 & $2(3 \%)$ & \\
\hline ALL & $16(84 \%)$ & $60(78 \%)$ & \\
\hline AML & $3(16 \%)$ & $8(11 \%)$ & \\
\hline $\mathrm{CML}$ & 0 & $4(5 \%)$ & \\
\hline \multicolumn{4}{|c|}{$\begin{array}{l}\text { Number of remissions } \\
\text { before TBI }\end{array}$} \\
\hline 0 & 0 & $2(3 \%)$ & 0.56 \\
\hline 1 & $7(42 \%)$ & $25(33 \%)$ & \\
\hline 2 & $10(58 \%)$ & $44(57 \%)$ & \\
\hline 3 & 0 & $5(7 \%)$ & \\
\hline \multicolumn{4}{|l|}{ Graft vs host disease } \\
\hline No & $3(15 \%)$ & $13(17 \%)$ & 0.89 \\
\hline Yes & $16(85 \%)$ & $63(83 \%)$ & \\
\hline Chronic & $5(31 \%)$ & $22(34 \%)$ & 0.78 \\
\hline Acute & $11(69 \%)$ & $41(66 \%)$ & \\
\hline \multicolumn{4}{|l|}{ Cranial irradiation } \\
\hline Yes $^{\mathrm{a}}$ & $4(20 \%)$ & $12(16 \%)$ & 0.58 \\
\hline No & $15(80 \%)$ & $64(84 \%)$ & \\
\hline
\end{tabular}

BAL, biphenotypic acute leukemia, L, lymphoma; ALL, acute lymphoblastic leukemia; AML, acute myeloid leukaemia; CML, chronic myeloid leukemia. ${ }^{a}$ Cranial irradiation: 18 Gy $(n=4), 15$ Gy $(n=1), 14$ Gy $(n=1), 12$ Gy $(n=1)$, $9 \mathrm{~Gy}(n=1), 8 \mathrm{~Gy}(n=2)$, and $6 \mathrm{~Gy}(n=5)$. Ocular globe irradiation: 6 Gy $(n=1)$.

\section{Methods}

All patients received 12 Gy fractionated TBI using the protocol (six fractions of $2 \mathrm{~Gy}$ for three consecutive days). Sex, primary disease, age at primary disease and at HSCT, the occurrence of both acute and chronic GVHD, the number of remissions before transplantation and previous cranial irradiation, if any, were recorded. Age at the time of the study was defined as the age at which the last ultrasound scan was performed or at which nodules were managed (biopsy and/or partial or total thyroidectomy according to the medical indication).

The results of thyroid ultrasound examination were recorded. The size, shape, echogenicity, and location of all solid nodules in the thyroid were recorded. We defined nodules as being $\geq 4 \mathrm{~mm}$ in diameter. All smaller nodules were considered to be micronodules. On this basis, patients were classified as having or not having nodules. If nodules were present, we also assessed the potential involvement of regional lymph nodes. When ultrasound scans revealed thyroid nodules $>8 \mathrm{~mm}$ in diameter, depending on the ultrasound characteristics of these nodules (i.e. microcalcifications, 
hypoechogenicity, irregular margins, and intranodular vascularity), a FNAB was performed (30). Surgery was performed in cases of malignant lesions, noninformative FNAB, or patient preference due to the large size of a benign nodule. Regular ultrasound scans were recommended for patients with nodules $\leq 8 \mathrm{~mm}$ in diameter and for benign lesions assessed by FNAB or with nonsuspicious ultrasound characteristics. Histopathological diagnosis was reviewed on a case-by-case basis. Thyroid nodules were classified into two groups: benign and malignant. Based on the medical records, malignant nodules were classified as papillary carcinoma, or as a follicular variant of papillary carcinoma when characteristics of nuclear changes in papillary carcinoma were described. Serum TSH and $\mathrm{FT}_{4}$ concentrations were determined by immunochemiluminescence using a Centaur CP, Siemens.

\section{Statistical analysis}

Results are expressed as numerical values (percentages) for categorical variables and as medians (25th-75th percentile) for continuous variables. The characteristics of different groups of patients were compared using $\chi^{2}$-tests or Fisher's exact tests for categorical variables and Wilcoxon tests for continuous variables. Cumulative incidence estimates of thyroid nodules (benign and malignant) were calculated from the time from TBI to the diagnosis of thyroid nodules. Death and absence of ultrasound scans during follow-up were treated as competing events, with times calculated from the time from TBI to the date of death and to the date of last contact respectively. Data were censored at the date of the last ultrasound scan (31). The variables associated with nodule occurrence were analyzed with the regression model for subdistributions of competing risks developed by Fine and Gray (32). The following variables were studied: age at TBI, ALL vs other types of cancer, GVHD, cranial irradiation, and hypothyroidism.

All tests were two-tailed with $P<0.05$ considered as significant. Statistical analyses were performed using the SAS 9.1 (SAS, Inc., Cary, NC, USA) and S-PLUS 6.2, Insightful Corp Software packages for PC.

\section{Results}

The cumulative incidence of thyroid nodule occurrence increased with increasing time from diagnosis and was at 5\% (95\% confidence interval (CI) $0-11 \%)$ and $24 \%(95 \%$ CI $11-37 \%) 5$ and 10 years after TBI respectively (Fig. 1).

\section{Ultrasound findings}

At least one nodule $(\geq 4 \mathrm{~mm})$ was found in $21(28 \%)$ patients. The nodules were either single $(n=11$ patients) or multiple $(n=10$ patients $)$, with two

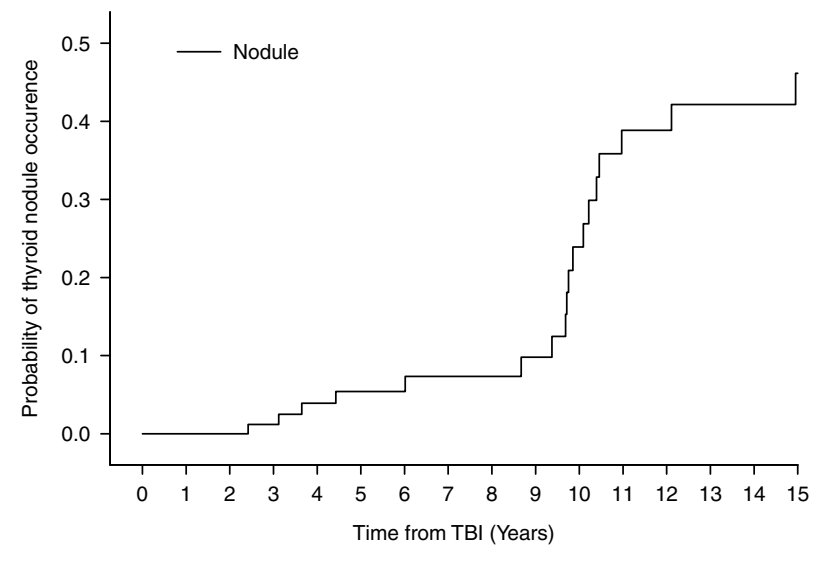

Figure 1 Cumulative incidence of the development of thyroid nodules after TBI preceding HSCT during childhood.

$(n=5)$, three $(n=3)$, or five $(n=2)$ nodules per patient. They were located either on the left ( $n=7$ patients) or right ( $n=6$ patients) thyroid lobe. The nodules were bilateral in eight $(38 \%)$ of the 21 patients. Nodule diameter ranged from 6 to $40 \mathrm{~mm}$, with a median value of $13.7(8-22) \mathrm{mm}$.

The characteristics of the 76 patients at the time of the study are given as a function of ultrasound findings, according to the presence or absence of thyroid nodules (Table 2). Patients with nodules were significantly younger at the time of TBI $(6.7(4.6-8.5)$ vs 9.0 (5.9$12.3)$ years, $P=0.04)$ and were older at the time of last ultrasound (17.1 (14-19) vs 13 (10.3-16.6), $P=0.005)$, resulting in a longer period of follow-up $(9.9(8.7-11)$ vs $3.6(2.1-6.5), P<0.001)$ than patients without nodules. Thirteen of the 21 patients with nodules had a previous ultrasound examination at a median of 3 (3-6.7) years before the last scan. On these previous scans, eight patients had no nodules and three had micronodules (Fig. 2). The proportion of patients with thyroid dysfunction at the time of ultrasound examination who had previously received cranial irradiation, were in remission at the time of TBI, or developed GVHD (either acute or chronic) was similar for patients with and without nodules.

\section{Histology findings}

Nodules were either benign $(n=15,71 \%)$ or malignant $(n=6,29 \%)$. The cumulative incidence of benign and malignant nodules was $16 \%(95 \%$ CI $4-27 \%)$ and $8 \%$ (95\% CI 0-16\%) respectively, 10 years after TBI (Fig. 3).

The characteristics of the patients diagnosed with benign or malignant thyroid nodules are indicated in Table 3. Patients with malignant nodules were slightly younger at the time of TBI, but the median time from TBI to nodule detection was similar in patients with benign and malignant thyroid nodules (10.1 (9.4-11.0) 
Table 2 Characteristics of participants according to the presence or absence of thyroid nodules, as assessed using ultrasound scans. Results are expressed as medians (25th-75th percentile).

\begin{tabular}{|c|c|c|c|}
\hline & $\begin{array}{c}\text { Patients with } \\
\text { nodules } \\
(n=21)\end{array}$ & $\begin{array}{c}\text { Patients } \\
\text { without } \\
\text { nodules } \\
(n=55)\end{array}$ & $P$ value \\
\hline \multicolumn{4}{|l|}{ Sex } \\
\hline Male & $12(57 \%)$ & $31(56 \%)$ & 0.36 \\
\hline Female & $9(42 \%)$ & $24(44 \%)$ & \\
\hline $\begin{array}{l}\text { Age at diagnosis } \\
\text { of hematological } \\
\text { disease (years) }\end{array}$ & $3.4(2.5-5.3)$ & $7.2(3.5-9.8)$ & 0.005 \\
\hline Age at TBI (years) & $6.7(4.6-8.5)$ & 9 (5.9-12.3) & 0.04 \\
\hline $\begin{array}{l}\text { Age at nodule } \\
\text { diagnosis or } \\
\text { last US (years) }\end{array}$ & $17.1(14-19)$ & $13.0(10.3-16.6)$ & 0.005 \\
\hline $\begin{array}{l}\text { Time between TBI } \\
\text { and last US (years) }\end{array}$ & $9.9(8.7 ; 11.0)$ & $3.6(2.1 ; 6.5)$ & $<0.001$ \\
\hline \multicolumn{4}{|l|}{ Type of cancer } \\
\hline $\mathrm{L}$ & 0 & $2(4 \%)$ & 0.08 \\
\hline BAL & 0 & $2(4 \%)$ & \\
\hline ALL & $16(76 \%)$ & $44(80 \%)$ & \\
\hline AML & $2(10 \%)$ & $6(11 \%)$ & \\
\hline CML & $3(14 \%)$ & $1(2 \%)$ & \\
\hline \multicolumn{4}{|l|}{$\begin{array}{l}\text { Number of remissions } \\
\text { before transplantation }\end{array}$} \\
\hline 0 & $1(5 \%)$ & $1(2 \%)$ & 0.41 \\
\hline 1 & $5(23 \%)$ & $20(36 \%)$ & \\
\hline 2 & $13(61 \%)$ & $31(56 \%)$ & \\
\hline 3 & $2(10 \%)$ & $3(6 \%)$ & \\
\hline \multicolumn{4}{|l|}{ Graft vs host disease } \\
\hline No & $5(15 \%)$ & $8(15 \%)$ & 0.33 \\
\hline Yes & $16(85 \%)$ & 47 (85\%) & \\
\hline Chronic & $5(31 \%)$ & $17(36 \%)$ & \\
\hline Acute & $11(69 \%)$ & $30(64 \%)$ & \\
\hline \multicolumn{4}{|l|}{ Cranial irradiation } \\
\hline Yes & $3(14 \%)$ & $9(16 \%)$ & 0.72 \\
\hline No & $18(86 \%)$ & $46(84 \%)$ & \\
\hline \multicolumn{4}{|l|}{ Hypothyroidism } \\
\hline Compensated & $3(14 \%)$ & $4(7 \%)$ & 0.6 \\
\hline $\begin{array}{l}\text { Transient } \\
\text { compensated }\end{array}$ & $2(9.5 \%)$ & $3(5 \%)$ & \\
\hline \multicolumn{4}{|l|}{ Uncompensated } \\
\hline Primary & 0 & $3(5 \%)^{a}$ & \\
\hline Central & 0 & $2(4 \%)^{b}$ & \\
\hline
\end{tabular}

L, lymphoma; BAL, biphenotypic acute leukemia; ALL, acute lymphoblastic leukemia; AML, acute myeloid leukemia; CML, chronic myeloid leukemia; US, ultrasound scan.

${ }^{a}$ Autoimmune thyroiditis $(n=1)$

${ }^{\mathrm{b}}$ Cranial irradiation 18 Gy $(n=1)$.

vs 9.3 (3.6-15.3) years). However, nodules were significantly larger in patients with malignant thyroid disease than in those with benign thyroid disease, with a median diameter of 25 (20-30) vs 10 (7-28) mm respectively, $P=0.01$ (Fig. 2 ).

No significant independent risk factors were identified by the multivariable competing risk model as a function of nodule occurrence. However, age at TBI and having hypothyroidism (compensated in all patients with nodules) were weakly associated with the cumulative incidence of developing subsequent nodules, with a subhazard ratio of 0.91 (95\% CI 0.80-1.02), $P=0.12$ and 2.78 (95\% CI 0.86-9.03), $P=0.09$ respectively.
Table 4 shows the characteristics of the six patients (three males and three females) with thyroid carcinoma. The time from TBI to nodule detection ranged from 2.2 to 15.3 years. Patients had either isolated $(n=4)$ or multiple nodules $(n=2$, patients 5 and 6$)$. In patients with multiple nodules, these nodules were found on one lobe $(n=1)$ or on one lobe and isthmus $(n=1)$. Histological analysis classified these tumors as follows: four papillary carcinomas and two follicular variants of papillary carcinomas. Bilateral lymph node metastasis was found in one patient with papillary carcinoma (patient 1). The limits of the tumor in one of the patients (patient 6) reached the borders of the thyroid gland, without vascular involvement. In these two patients (patients 1 and 6), carcinoma was diagnosed 3.6 and 9.2 years after irradiation respectively. No systemic metastasis was observed in any of these patients. Thyroid function was normal for all but one patient

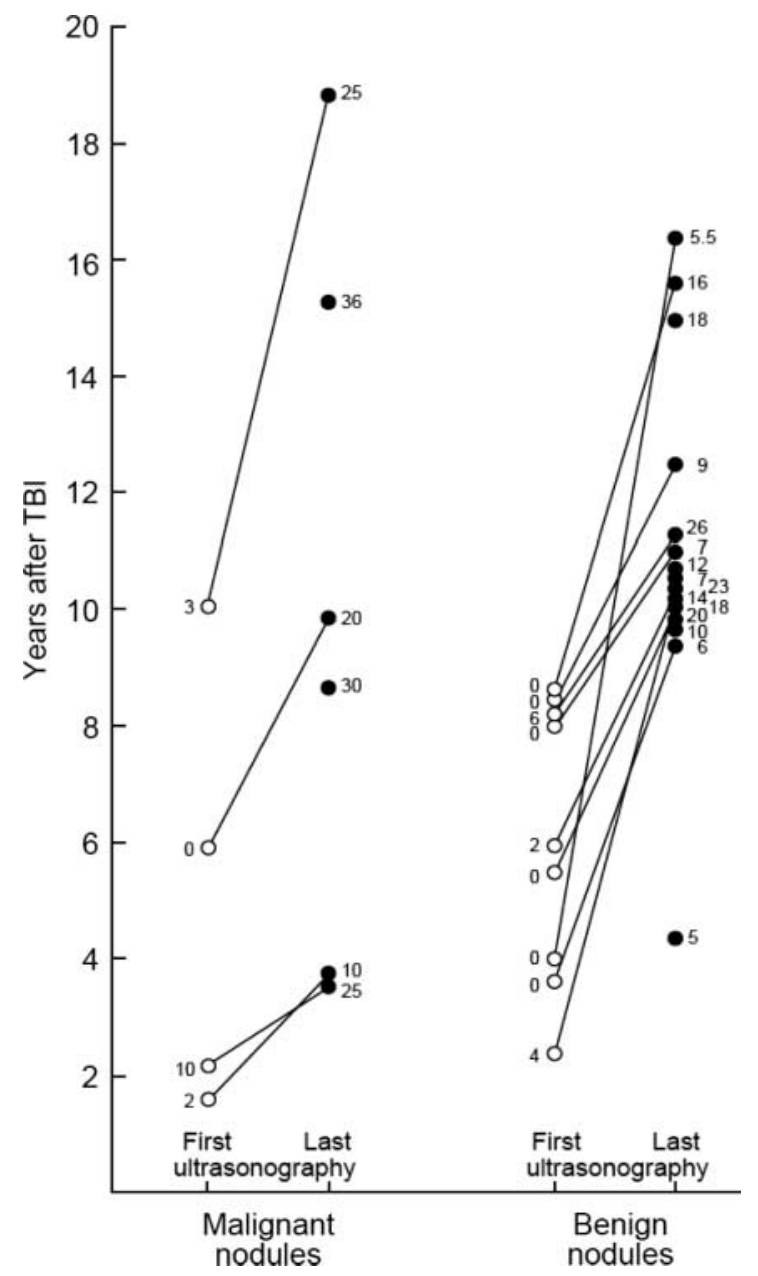

Figure 2 Distribution of the time from TBI to nodule $(\geq 4 \mathrm{~mm})$ or micronodule $(<4 \mathrm{~mm})$ detection and nodule dimensions in patients diagnosed with malignant or benign nodules. Open circles correspond to the first ultrasound scan after TBI and closed circles correspond to the most recent ultrasound scan. Nodule dimensions are expressed in millimeters. 


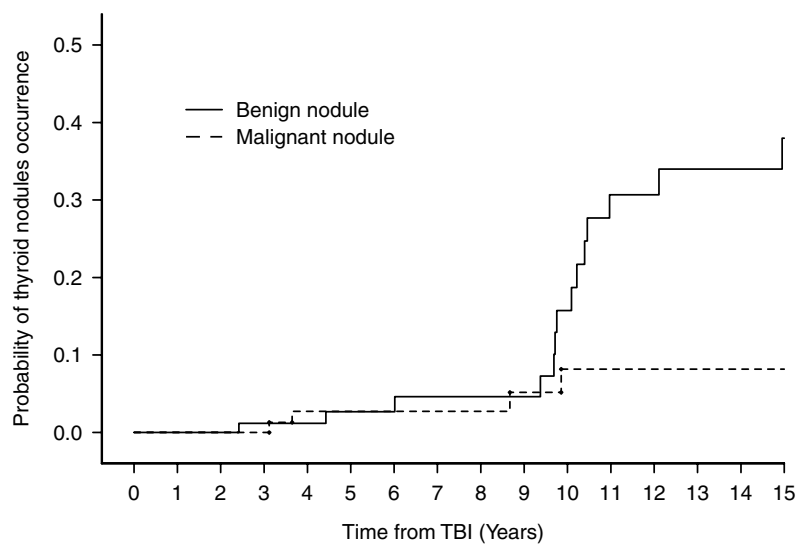

Figure 3 Cumulative incidence of developing benign (black line) or malignant (dotted line) thyroid nodules after TBI preceding HSCT during childhood.

who presented with peripheral subclinical compensated hypothyroidism. Total thyroidectomy was performed in all patients, with additional ${ }^{131}$ I treatment in two cases due to bilateral cervical lymph node involvement and residual nontumoral thyroid tissue, in patients 1 and 2 respectively. All patients achieved disease-free status.

\section{Discussion}

The results of this study extend our knowledge of the high frequency of thyroid nodules and carcinomas among adolescents and young adult patients who received TBI as part of conditioning regimens for HSCT to treat malignant hematological disease during childhood. The cumulative incidence of nodule occurrence increased with increasing time from diagnosis.

Estimates of the prevalence of thyroid nodules in the general population of children depend on the method of detection and range from $1 \%$ for detection by palpation to $3 \%$ for detection using ultrasound scans. This prevalence increases with age, particularly during puberty and adulthood, reaching about $20 \%$ in midlife in countries with no marked iodine deficiency (30, 33). Thyroid nodules are less common in children than in adults, but the risk of malignancy is much higher in children, with an estimation of $10-25 \%$ of thyroid nodules being malignant vs only $5 \%$ in adults. Differentiated thyroid carcinoma is a rare disorder in children, accounting for up to 3\% of all children with cancer, with an annual incidence of $0.5-1 /$ million children (34). The sex ratio is close to 1 before puberty, but a female preponderance is observed later in life (35). Most of the cancers observed are papillary carcinoma and its follicular variants, with no observed systemic metastasis and the probability of developing metastatic disease is small in these patients. Exposure to low-dose ionizing irradiation of the head and neck has been shown to be associated with an increase in the incidence of thyroid nodules and carcinoma during childhood $(11,13,16)$. However, the level of excess risk remains unclear, as not all the population systematically underwent ultrasound screening and some were not screened at all. In this study, patients were followed for a median of 5.1 years after TBI, and thyroid nodules, detected during screening by ultrasound scan, were observed in $21(28 \%)$ of the 76 patients. The median interval between fractionated TBI (1200 cGy) and nodule detection was 9.9 years. Six $(29 \%)$ of the 21 patients with nodules were diagnosed with thyroid carcinoma, corresponding to an incidence of $8 \%$ for thyroid cancer in the studied population, a figure much higher than that in the general French population of similar age (36) and than that of the recurrence of malignant disease after leukemia, lymphoma, or other cancers have been cured in childhood $(19,37)$, even though studies evaluating the incidence of a second tumor have highlighted the relationship between the development of a second cancer in the thyroid and exposure to radiation (38).

Table 3 Characteristics of patients with malignant or benign thyroid nodules. Results are expressed as medians (25th-75th percentile).

\begin{tabular}{|c|c|c|c|}
\hline & $\begin{array}{c}\text { Malignant } \\
\text { nodule }(n=6)\end{array}$ & $\begin{array}{l}\text { Benign nodule } \\
(n=15)\end{array}$ & $P$ value \\
\hline \multicolumn{4}{|l|}{ Sex } \\
\hline Male & $3(50 \%)$ & $9(60 \%)$ & 0.68 \\
\hline Female & $3(50 \%)$ & $6(40 \%)$ & \\
\hline $\begin{array}{l}\text { Age at diagnosis of } \\
\text { hematological } \\
\text { disease }\end{array}$ & $2.1(1.5-2.8)$ & $4.4(3.0-6.0)$ & 0.02 \\
\hline Age at TBI (years) & $6.1(5.6-8.6)$ & $7(4.1-8.4)$ & 0.66 \\
\hline $\begin{array}{l}\text { Age at nodule } \\
\text { diagnosis (years) }\end{array}$ & $16.4(14.3-21.7)$ & $17.1(13.9-19.1)$ & 0.93 \\
\hline $\begin{array}{l}\text { Time between TBI and } \\
\text { last US (years) }\end{array}$ & $9.3(3.6-15.3)$ & $10.1(9.4-11.0)$ & 0.75 \\
\hline \multicolumn{4}{|l|}{$\begin{array}{l}\text { Number of remissions } \\
\text { before transplantation }\end{array}$} \\
\hline 0 & 0 & $1(7 \%)$ & 0.79 \\
\hline 1 & $1(17 \%)$ & $4(26 \%)$ & \\
\hline 2 & $4(66 \%)$ & $9(60 \%)$ & \\
\hline 3 & $1(17 \%)$ & $1(7 \%)$ & \\
\hline \multicolumn{4}{|l|}{ Graft vs host disease } \\
\hline No & $1(17 \%)$ & $4(11 \%)$ & 0.63 \\
\hline Yes & $5(83 \%)$ & $11(73 \%)$ & \\
\hline Chronic & $2(40 \%)$ & $2(18 \%)$ & 0.57 \\
\hline Acute & $3(60 \%)$ & $9(82 \%)$ & \\
\hline \multicolumn{4}{|l|}{ Cranial irradiation } \\
\hline Yes & $1(17 \%)$ & $2(13 \%)$ & 0.85 \\
\hline No & 5 (83\%) & $13(87 \%)$ & \\
\hline $\begin{array}{l}\text { Nodule size at last } \\
\text { US }(\mathrm{mm})\end{array}$ & $25(20-30)$ & $10(7-18)$ & 0.01 \\
\hline $\begin{array}{l}\text { Number of nodules at } \\
\text { last US }\end{array}$ & $1(1-2)$ & $2(1-3)$ & 0.43 \\
\hline \multicolumn{4}{|l|}{ Nodules } \\
\hline Multiple & $2(33 \%)$ & $10(66 \%)$ & 0.33 \\
\hline Solitary & $4(66 \%)$ & $5(33 \%)$ & \\
\hline \multicolumn{4}{|l|}{ Hypothyroidism } \\
\hline Compensated & $1(16 \%)$ & $2(3.6 \%)$ & 0.76 \\
\hline $\begin{array}{l}\text { Transient } \\
\text { compensated }\end{array}$ & $1(16 \%)$ & $1(1.8 \%)$ & \\
\hline
\end{tabular}

US, ultrasound scan. 


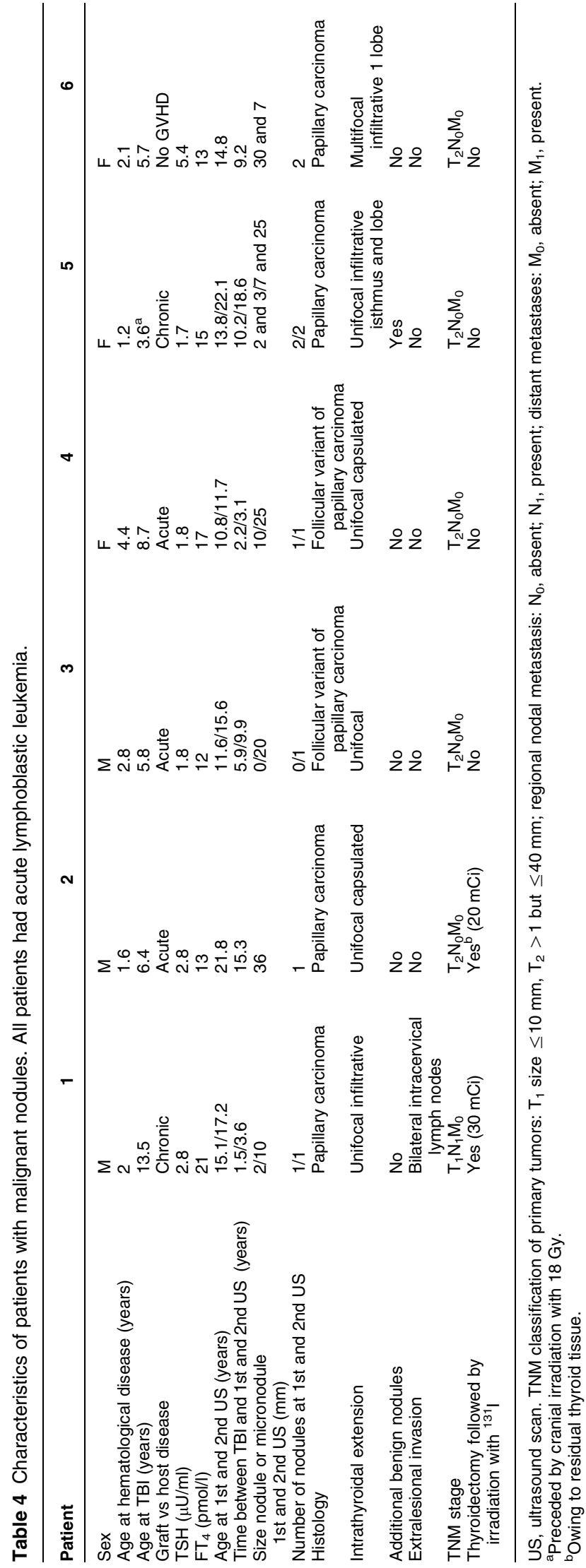

The role of irradiation in causing thyroid nodules, carcinomas, and thyroid dysfunction has been clearly demonstrated in Hodgkin's disease patients undergoing cervical irradiation (39). However, studies on the effects of TBI preceding HSCT have mostly been limited to thyroid dysfunction. They have shown overt or, more frequently, subclinical hypothyroidism in $10-60 \%$ of patients, with a single dose more deleterious than a fractionated dose $(25,26,27,40,41,42,43)$. Consistent with most previous studies, peripheral subclinical hypothyroidism was found in $12(16 \%)$ patients in our studied population and was transient in five of these patients. The role of chronic hyperstimulation of the thyroid gland due to subclinical hypothyroidism in increasing the risk of thyroid nodule and carcinoma onset and/or progression and the need for $\mathrm{L}-\mathrm{T}_{4}$ therapy in patients with this biochemical condition, which, as shown here, is often transient, remain a matter of debate $(44,45,46,47)$. Prospective studies on a larger number of children are required to further clarify whether chronic subclinical hypothyroidism in this population is associated with relevant abnormalities that may require $\mathrm{L}-\mathrm{T}_{4}$ treatment.

Data on the development of thyroid carcinoma after TBI are scarce, as cohorts of patients are not systematically screened by ultrasound scans followed by FNBA and published studies have essentially concerned case series or case reports. A large follow-up study on 3182 patients receiving TBI before bone marrow transplantation for acute leukemia diagnosed before the age of 17 years reported that five patients had thyroid carcinoma, but no systematic ultrasound monitoring was performed during the median follow-up period of 3.6 (1-20.7) years (48). Thyroid carcinoma has been sporadically reported after latency periods of between 5 years and up to 15 or 30 years after exposure, depending on the study $(4,49,50)$. With the increasing use of ultrasound scans and FNAB, thyroid carcinoma tends to be diagnosed very accurately at early stages (51). Only two other retrospective studies reported the results of ultrasound examinations for the detection of thyroid nodules and/or carcinoma during the follow-up of patients receiving TBI as part of conditioning regimens for HSCT during childhood $(22,24)$. One of these studies on 42 patients surviving for at least 10 years after TBI, in which earlier effects were not investigated, showed that nodules were present in $60 \%$ of the patients and that thyroid carcinoma occurred in six $(25 \%)$ of the 24 patients with nodules after a median of 12 years of follow-up (22), consistent with the diagnosis of thyroid carcinoma for $29 \%$ of the nodules in our study. The relatively high incidence of thyroid nodules, at $60 \%$ in this study, may reflect the longer period of follow-up after irradiation and/or the lower dose of irradiation used for TBI. In the group of 24 patients with nodules, 20 belonged to the subgroup of 25 patients who had received $990 \mathrm{cGy}$, whereas only four patients belonged to the group of 17 patients 
treated with $1200 \mathrm{cGy}$. The other study focused on patients with thyroid carcinoma only, which was found in eight $(7 \%)$ of the 113 patients investigated with a median of 8.5 years (range: 3.1-15.7) after TBI (24). This frequency was similar to the $8 \%$ reported here for thyroid carcinoma, with a similar follow-up period. Histological diagnosis, with a preponderance of papillary and follicular-type carcinoma, was also similar between the two studies. As in our study, neither young age at irradiation nor any of the other factors studied were found to be a significant risk factor for the development of thyroid carcinoma, probably because of the limited number of patients studied. It is also unclear what proportion of thyroid nodules, including thyroid carcinoma, would have become clinically overt if not identified by ultrasound screening. However, the excess risk of radiation-related nodules may be overestimated due to an early detection bias as a result of ultrasound screening, given that thyroid nodules are found in a large proportion of the general population on autopsy.

In this study, we were able to document thyroid ultrasound screening for thyroid nodules in $80 \%$ of a well-defined population exposed to TBI during childhood. Despite the relatively small size of the study population, which was nevertheless the largest series investigated to date, thyroid nodules and carcinomas were found in a significant proportion of this population. The main limitation of our study was the observational nature of retrospective data collection. We did not document longitudinal changes in the thyroid tissue in most patients, but the relative difference in size between benign and malignant nodules found here may reflect the known tendency of thyroid cancers to grow rapidly in patients at these ages (52). Moreover, we cannot rule out the possibility that patients who were not carefully followed by regular ultrasound scans had presented thyroid nodules and/or carcinoma sooner after TBI, as a thyroid carcinoma nodule was diagnosed as early as 2.2 years after TBI in one of our patients. Thus, the incidence of thyroid nodules may be underestimated due to the absence of standardized follow-up.

In conclusion, these results have important clinical implications. They highlight the need for thyroid function investigations and ultrasound scans followed by FNAB of thyroid nodules when required, every 1-3 years, depending on the presence or absence of thyroid dysfunction, small nodules, and duration of follow-up. This screening should begin at the time of TBI, to provide baseline information, and extend over a followup period of at least 30 years, to facilitate the detection of microcarcinomas that have a more favorable prognosis than larger tumors (53). However, evidencebased rational strategies concerning the duration of follow-up, the time interval between screening events by ultrasound scan, and thyroid function assessments detecting even subtle thyroid dysfunction and treatment are lacking, and little is known about risk/benefit ratio for health outcomes. Additional, prospective, population-based studies on larger groups of patients should be carried out in the future, together with investigations of the unknown potential risk of thyroid carcinoma and its aggressiveness in patients with nodules.

\section{Declaration of interest}

The authors declare that there is no conflict of interest that could be perceived as prejudicing the impartiality of the research reported.

\section{Funding}

This research did not receive any specific grant from any funding agency in the public, commercial or not-for-profit sector.

\section{Acknowledgements}

The authors thank Meriem Benmerad for her invaluable contribution to the statistical analysis.

\section{References}

1 Kaplan MM, Garnick MB, Gelber R, Li FP, Cassady JR, Sallan SE, Fine WE \& Sack MJ. Risk factors for thyroid abnormalities after neck irradiation for childhood cancer. American Journal of Medicine 198374 272-280. (doi:10.1016/0002-9343(83)90626-5)

2 Schneider AB, Ron E, Lubin J, Stovall M \& Gierlowski TC. Doseresponse relationships for radiation-induced thyroid cancer and thyroid nodules: evidence for the prolonged effects of radiation on the thyroid. Journal of Clinical Endocrinology and Metabolism 1993 77 362-369. (doi:10.1210/jc.77.2.362)

3 Schneider AB, Shore-Freedman E, Ryo UY, Bekerman C, Favus M \& Pinsky S. Radiation-induced tumors of the head and neck following childhood irradiation. Prospective studies. Medicine 198564 1-15. (doi:10.1097/00005792-198501000-00001)

4 Ron E, Modan B, Preston D, Alfandary E, Stovall M \& Boice JD Jr. Thyroid neoplasia following low-dose radiation in childhood. Pediatric Research 1989120 516-531.

5 Mihailescu DV \& Schneider AB. Size, number, and distribution of thyroid nodules and the risk of malignancy in radiation-exposed patients who underwent surgery. Journal of Clinical Endocrinology and Metabolism 200893 2188-2193. (doi:10.1210/jc.20080055)

6 Fleming ID, Black TL, Thompson EI, Pratt C, Rao B \& Hustu O. Thyroid dysfunction and neoplasia in children receiving neck irradiation for cancer. Cancer 198555 1190-1194. (doi:10. 1002/1097-0142(19850315)55:6 < 1190::AID-CNCR2820550 $609>3.0 . \mathrm{CO} ; 2-6)$

7 Shafford EA, Kingston JE, Healy JC, Webb JA, Plowman PN \& Reznek RH. Thyroid nodular disease after radiotherapy to the neck for childhood Hodgkin's disease. British Journal of Cancer $1999 \mathbf{8 0}$ 808-814. (doi:10.1038/sj.bjc.6690425)

8 Sklar C, Whitton J, Mertens A, Stovall M, Green D, Marina N, Greffe B, Wolden S \& Robison L. Abnormalities of the thyroid in survivors of Hodgkin's disease: data from the Childhood Cancer Survivor Study. Journal of Clinical Endocrinology and Metabolism 200085 3227-3232. (doi:10.1210/jc.85.9.3227)

9 de Vathaire F, Hardiman C, Shamsaldin A, Campbell S, Grimaud E, Hawkins M, Raquin M, Oberlin O, Diallo I, Zucker JM, Panis X, Lagrange JL, Daly-Schveitzer N, Lemerle J, Chavaudra J, Schlumberger M \& Bonaiti C. Thyroid carcinomas after irradiation for a first cancer during childhood. Archives of Internal Medicine 1999159 2713-2719. (doi:10.1001/archinte.159.22.2713) 
10 Acharya S, Sarafoglou K, LaQuaglia M, Lindsley S, Gerald W, Wollner N, Tan C \& Sklar C. Thyroid neoplasms after therapeutic radiation for malignancies during childhood or adolescence. Cancer 200397 2397-2403. (doi:10.1002/cncr.11362)

11 Taylor AJ, Croft AP, Palace AM, Winter DL, Reulen RC, Stiller CA, Stevens MC \& Hawkins MM. Risk of thyroid cancer in survivors of childhood cancer: results from the British Childhood Cancer Survivor Study. International Journal of Cancer $2009 \mathbf{1 2 5}$ 2400-2405. (doi:10.1002/ijc.24581)

12 Massimino M, Gandola L, Mattavelli F, Pizzi N, Seregni E, Pallotti F, Spreafico F, Marchiano A, Terenziani M, Cefalo G, Biassoni V, Meazza C, Trecate G \& Collini P. Radiation-induced thyroid changes: a retrospective and a prospective view. European Journal of Cancer 200945 2546-2551. (doi:10.1016/j.ejca. 2009.06.009)

13 Sinnott B, Ron E \& Schneider AB. Exposing the thyroid to radiation: a review of its current extent, risks, and implications. Endocrine Reviews 201031 756-773. (doi:10.1210/er.20100003)

14 Ron E, Lubin JH, Shore RE, Mabuchi K, Modan B, Pottern LM, Schneider AB, Tucker MA \& Boice JD Jr. Thyroid cancer after exposure to external radiation: a pooled analysis of seven studies. Pediatric Research 1995141 259-277.

15 Ronckers CM, Sigurdson AJ, Stovall M, Smith SA, Mertens AC, Liu Y, Hammond S, Land CE, Neglia JP, Donaldson SS, Meadows AT, Sklar CA, Robison LL \& Inskip PD. Thyroid cancer in childhood cancer survivors: a detailed evaluation of radiation dose response and its modifiers. Pediatric Research $2006 \mathbf{1 6 6}$ 618-628. (doi:10.1667/RR3605.1)

16 Bhatti P, Veiga LH, Ronckers CM, Sigurdson AJ, Stovall M, Smith SA, Weathers R, Leisenring W, Mertens AC, Hammond S, Friedman DL, Neglia JP, Meadows AT, Donaldson SS, Sklar CA, Robison LL \& Inskip PD. Risk of second primary thyroid cancer after radiotherapy for a childhood cancer in a large cohort study: an update from the Childhood Cancer Survivor Study. Pediatric Research 2010174 741-752. (doi:10.1667/RR2240.1)

17 Inskip PD. Thyroid cancer after radiotherapy for childhood cancer. Medical and Pediatric Oncology 200136 568-573. (doi:10.1002/ mpo.1132)

18 Sigurdson AJ, Ronckers CM, Mertens AC, Stovall M, Smith SA, Liu Y, Berkow RL, Hammond S, Neglia JP, Meadows AT, Sklar CA, Robison LL \& Inskip PD. Primary thyroid cancer after a first tumour in childhood (the Childhood Cancer Survivor Study): a nested case-control study. Lancet 2005365 2014-2023. (doi:10. 1016/S0140-6736(05)66695-0)

19 Maule M, Scelo G, Pastore G, Brennan P, Hemminki K, Tracey E, Sankila R, Weiderpass E, Olsen JH, McBride ML, Brewster DH, Pompe-Kirn V, Kliewer EV, Chia KS, Tonita JM, Martos C, Jonasson JG, Merletti F \& Boffetta P. Risk of second malignant neoplasms after childhood leukemia and lymphoma: an international study. Journal of the National Cancer Institute 200799 790-800. (doi:10.1093/jnci/djk180)

20 Chow EJ, Friedman DL, Stovall M, Yasui Y, Whitton JA, Robison LL \& Sklar CA. Risk of thyroid dysfunction and subsequent thyroid cancer among survivors of acute lymphoblastic leukemia: a report from the Childhood Cancer Survivor Study. Pediatric Blood $\mathcal{E}$ Cancer 200953 432-437. (doi:10.1002/pbc.22082)

21 Veiga LH, Bhatti P, Ronckers CM, Sigurdson AJ, Stovall M, Smith SA, Weathers R, Leisenring W, Mertens AC, Hammond S, Neglia JP, Meadows AT, Donaldson SS, Sklar CA, Friedman DL, Robison LL \& Inskip PD. Chemotherapy and thyroid cancer risk: a report from the Childhood Cancer Survivor Study. Cancer Epidemiology, Biomarkers \& Prevention 201221 92-101. (doi:10.1158/1055-9965.EPI-11-0576)

22 Faraci M, Barra S, Cohen A, Lanino E, Grisolia F, Miano M, Foppiano F, Sacco O, Cabria M, De Marco R, Stella G, Dallorso S, Bagnasco F, Vitale V, Dini G \& Haupt R. Very late nonfatal consequences of fractionated TBI in children undergoing bone marrow transplant. International Journal of Radiation Oncology, Biology, Physics 200563 1568-1575. (doi:10.1016/j.ijrobp. 2005.04.031)
23 Uderzo C, van Lint MT, Rovelli A, Weber G, Castellani MR, Bacigalupo A, Masera N \& Cohen A. Papillary thyroid carcinoma after total body irradiation. Archives of Disease in Childhood 1994 71 256-258. (doi:10.1136/adc.71.3.256)

24 Cohen A, Rovelli A, van Lint MT, Merlo F, Gaiero A, Mulas R, Balduzzi A, Corti P, Uderzo C \& Bacigalupo A. Secondary thyroid carcinoma after allogeneic bone marrow transplantation during childhood. Bone Marrow Transplantation 200128 1125-1128. (doi:10.1038/sj.bmt.1703290)

25 Ishiguro $\mathrm{H}$, Yasuda Y, Tomita Y, Shinagawa T, Shimizu T, Morimoto T, Hattori K, Matsumoto M, Inoue H, Yabe H, Yabe M, Shinohara O \& Kato S. Long-term follow-up of thyroid function in patients who received bone marrow transplantation during childhood and adolescence. Journal of Clinical Endocrinology and Metabolism 200489 5981-5986. (doi:10.1210/jc.2004-0836)

26 Flandin I, Hartmann O, Michon J, Pinkerton R, Coze C, Stephan JL, Fourquet B, Valteau-Couanet D, Bergeron C, Philip T \& Carrie C. Impact of TBI on late effects in children treated by megatherapy for Stage IV neuroblastoma. A study of the French Society of Pediatric Oncology. International Journal of Radiation Oncology, Biology, Physics 200664 1424-1431. (doi:10.1016/j.ijrobp.2005.10. 020)

27 Berger C, Le-Gallo B, Donadieu J, Richard O, Devergie A, Galambrun C, Bordigoni P, Vilmer E, Plouvier E, Perel Y, Michel G \& Stephan JL. Late thyroid toxicity in 153 long-term survivors of allogeneic bone marrow transplantation for acute lymphoblastic leukaemia. Bone Marrow Transplantation 200535 991-995. (doi:10.1038/sj.bmt.1704945)

28 Crom DB, Kaste SC, Tubergen DG, Greenwald CA, Sharp GB \& Hudson MM. Ultrasonography for thyroid screening after head and neck irradiation in childhood cancer survivors. Medical and Pediatric Oncology 199728 15-21. (doi:10.1002/(SICI)1096911X(199701)28:1<15::AID-MPO4> 3.0.CO;2-W)

29 Rosen IB, Azadian A, Walfish PG, Salem S, Lansdown E \& Bedard YC. Ultrasound-guided fine-needle aspiration biopsy in the management of thyroid disease. American Journal of Surgery 1993 166 346-349. (doi:10.1016/S0002-9610(05)80329-0)

30 Niedziela M. Pathogenesis, diagnosis and management of thyroid nodules in children. Endocrine-Related Cancer 200613 427-453. (doi:10.1677/erc.1.00882)

31 Gooley TA, Leisenring W, Crowley J \& Storer BE. Estimation of failure probabilities in the presence of competing risks: new representations of old estimators. Statistics in Medicine 1999 18 695-706. (doi:10.1002/(SICI)1097-0258(19990330)18:6< 695::AID-SIM60> 3.0.CO;2-0)

32 Fine JP \& Gray RJ. A proportional hazards model for the subdistribution of a competing risk. Journal of the American Statistical Association 199994 496-509.

33 Gharib H, Papini E \& Paschke R. Thyroid nodules: a review of current guidelines, practices, and prospects. European Journal of Endocrinology 2008159 493-505. (doi:10.1530/EJE-08-0135)

34 Greenlee RT, Hill-Harmon MB, Murray T \& Thun M. Cancer statistics. CA: A Cancer Journal for Clinicians 200151 15-36. (doi:10.3322/canjclin.51.1.15)

35 Leboulleux S, Baudin E, Hartl DW, Travagli JP \& Schlumberger M. Follicular cell-derived thyroid cancer in children. Hormone Research 200563 145-151. (doi:10.1159/000084717)

36 Reguerre Y, Lacour B, Andre N, Claude L, Hameury F, Lavrand F, Kalfa N, Peuchmaur M \& Orbach D. Epidemiology and management of rare paediatric tumours within the framework of the French Society for Children Cancer. Bulletin du Cancer 201097 1041-1045. (doi:10.1684/bdc.2010.1169)

37 Neglia JP, Meadows AT, Robison LL, Kim TH, Newton WA, Ruymann FB, Sather HN \& Hammond GD. Second neoplasms after acute lymphoblastic leukemia in childhood. New England Journal of Medicine 1991325 1330-1336. (doi:10.1056/NEJM1991110 73251902)

38 Friedman DL, Whitton J, Leisenring W, Mertens AC, Hammond S, Stovall M, Donaldson SS, Meadows AT, Robison LL \& Neglia JP. 
Subsequent neoplasms in 5-year survivors of childhood cancer: the Childhood Cancer Survivor Study. Journal of the National Cancer Institute 2010102 1083-1095. (doi:10.1093/jnci/djq238)

39 Hancock SL, Cox RS \& McDougall IR. Thyroid diseases after treatment of Hodgkin's disease. New England Journal of Medicine 1991325 599-605. (doi:10.1056/NEJM199108293250902)

40 Sklar CA, Kim TH \& Ramsay NK. Thyroid dysfunction among long-term survivors of bone marrow transplantation. American Journal of Medicine 198273 688-694. (doi:10.1016/00029343(82)90411-9)

41 Sanders JE. Endocrine problems in children after bone marrow transplant for hematologic malignancies. The long-term follow-up team. Bone Marrow Transplantation 19918 (Suppl 1) 2-4.

42 Thomas BC, Stanhope R, Plowman PN \& Leiper AD. Endocrine function following single fraction and fractionated total body irradiation for bone marrow transplantation in childhood. Acta Endocrinologica 1993128 508-512.

43 Boulad F, Bromley M, Black P, Heller G, Sarafoglou K, Gillio A, Papadopoulos E \& Sklar C. Thyroid dysfunction following bone marrow transplantation using hyperfractionated radiation. Bone Marrow Transplantation 199515 71-76. (doi:10.1038/jcbfm. 1995.8)

44 Rivas M \& Santisteban P. TSH-activated signaling pathways in thyroid tumorigenesis. Molecular and Cellular Endocrinology 2003 213 31-45. (doi:10.1016/j.mce.2003.10.029)

45 Gharib H, Tuttle RM, Baskin HJ, Fish LH, Singer PA \& McDermott MT. Subclinical thyroid dysfunction: a joint statement on management from the American Association of Clinical Endocrinologists, the American Thyroid Association, and the Endocrine Society. Journal of Clinical Endocrinology and Metabolism 200590 581-585 (discussion 586-587). (doi:10.1210/jc.20041231)

46 Villar HC, Saconato H, Valente O \& Atallah AN. Thyroid hormone replacement for subclinical hypothyroidism. Cochrane Database of Systematic Reviews 2007 CD003419.

47 Biondi B \& Cooper DS. The clinical significance of subclinical thyroid dysfunction. Endocrine Reviews $2008 \quad 29$ 76-131. (doi:10.1210/er.2006-0043)
48 Socie G, Curtis RE, Deeg HJ, Sobocinski KA, Filipovich AH, Travis LB, Sullivan KM, Rowlings PA, Kingma DW, Banks PM, Travis WD, Witherspoon RP, Sanders J, Jaffe ES \& Horowitz MM. New malignant diseases after allogeneic marrow transplantation for childhood acute leukemia. Journal of Clinical Oncology 200018 348-357.

49 Curtis RE, Rowlings PA, Deeg HJ, Shriner DA, Socie G, Travis LB, Horowitz MM, Witherspoon RP, Hoover RN, Sobocinski KA, Fraumeni JF Jr \& Boice JD Jr. Solid cancers after bone marrow transplantation. New England Journal of Medicine 1997336 897-904. (doi:10.1056/NEJM199703273361301)

50 Gow KW, Lensing S, Hill DA, Krasin MJ, McCarville MB, Rai SN, Zacher M, Spunt SL, Strickland DK \& Hudson MM. Thyroid carcinoma presenting in childhood or after treatment of childhood malignancies: An institutional experience and review of the literature. Journal of Pediatric Surgery 200338 1574-1580. (doi:10.1016/S0022-3468(03)00563-3)

51 Brignardello E, Corrias A, Isolato G, Palestini N, Cordero di Montezemolo L, Fagioli F \& Boccuzzi G. Ultrasound screening for thyroid carcinoma in childhood cancer survivors: a case series. Journal of Clinical Endocrinology and Metabolism 200893 4840-4843. (doi:10.1210/jc.2008-1528)

52 Vriens MR, Moses W, Weng J, Peng M, Griffin A, Bleyer A, Pollock BH, Indelicato DJ, Hwang J \& Kebebew E. Clinical and molecular features of papillary thyroid cancer in adolescents and young adults. Cancer 2011117 259-267. (doi:10.1002/cncr. 25369)

53 Roti E, Rossi R, Trasforini G, Bertelli F, Ambrosio MR, Busutti L, Pearce EN, Braverman LE \& Degli Uberti EC. Clinical and histological characteristics of papillary thyroid microcarcinoma: results of a retrospective study in 243 patients. Journal of Clinical Endocrinology and Metabolism 200691 2171-2178. (doi:10. 1210/jc.2005-2372)

Received 27 January 2012

Revised version received 26 April 2012

Accepted 22 May 2012 